\title{
Study on the Effective Range of Local Ventilation in the Driving Face of Single Head Roadway
}

\author{
Yuanwei Hao, Yong Wang \\ National Engineering Research Center for Coal Gas Control, Huainan, China \\ Email: 869289917@qq.com
}

How to cite this paper: Hao, Y.W. and Wang, Y. (2020) Study on the Effective Range of Local Ventilation in the Driving Face of Single Head Roadway. World Journal of Engineering and Technology, 8, 50-59. https://doi.org/10.4236/wjet.2020.81006

Received: December 20, 2019

Accepted: January 7, 2020

Published: January 10, 2020

Copyright (C) 2020 by author(s) and Scientific Research Publishing Inc. This work is licensed under the Creative Commons Attribution International License (CC BY 4.0).

http://creativecommons.org/licenses/by/4.0/

\section{cc) (i) Open Access}

\begin{abstract}
The traditional research considers that the effective range of forced local ventilation in single head tunnel is the horizontal distance from the jet exit section to the rotary section, but there is a low wind speed area at the end of the range which can not completely and effectively release toxic and harmful gases. In this area, due to the small jet energy, there is no way to effectively remove the toxic and harmful gases produced in the driving process, which seriously affects the safety of the mine. Therefore, the reasonable definition of the effective range of the forced local ventilation of the single head tunnel can not only improve the theory of the local ventilation of the mine, but also prevent the accumulation of gas and ensure the life safety of the employees. In this paper, the definition of effective range of local ventilation in single head heading face is put forward, and the rationality of the definition of effective range is verified by numerical simulation. On the basis of reasonable definition of effective range, the relationship between wind speed and effective range under different ventilation modes is studied by numerical simulation. The results show that when the wind speed at the outlet of the air duct is less than $20 \mathrm{~m} / \mathrm{s}$, the effective range changes rapidly with the outlet wind speed, and after more than $20 \mathrm{~m} / \mathrm{s}$, the effect of wind speed on the effective range is gradually weakened. Under the same exit wind speed, the effective range of parallel and coplanar air inlet is much greater than that of single air inlet.
\end{abstract}

\section{Keywords}

Effective Range, Numerical Simulation, Tunneling Ventilation, Wind Speed, Ventilation Pattern

\section{Introduction}

With the development of China's social economy, the demand for coal resources 
is also increasing. In order to meet the needs of development, China's coal mining enterprises are also constantly exploring potential and improving production capacity. Coal mine gas disaster seriously restricts the production capacity of China's coal mines. Only by controlling gas accidents and stabilizing the overall situation of safety production, can we ensure the healthy development of China's coal industry. In the process of mining, the gas concentration in the accumulation area is high and widely distributed, which is easy to cause gas explosion and gas combustion accidents, and it is a major hazard source of the mine [1] [2]. In the process of exposing the coal seam in the driving face, the gas emission is large, and local ventilation is adopted, which is easy to cause gas accumulation and gas accidents. Therefore, it is of great practical significance to fully grasp the air flow state and gas diffusion law of the driving face for the prevention of gas explosion accidents, the control of major hazard sources and the improvement of the production efficiency of the driving face.

Since the 1980s, scholars at home and abroad have carried out a lot of experimental research on the air flow state of driving face. Internationally, Nakayama and other scholars in Japan have obtained the distribution of air flow in the driving tunnel by using the method of laboratory measurement, and Ichinose Masatomo and other scholars have analyzed the gas distribution in the driving tunnel by using the method of field measurement in Japan [3]. Rao, an Australian scholar, used the method of hydrodynamics to simulate the flow state of the air flow in the working face and combined with the research results to discuss the dust reduction effect [4]. Japanese scholars Tomita Shinji, Inoue Masahiro, et al. used the method of similar simulation experiment to study the gas emission in the driving face, gave the gas concentration distribution law in the roadway, and considered that the state of the air flow field was affected by the position of the air duct outlet [5]. American scholar I. M. Konduri and other scholars used numerical analysis method to study the air flow in the single head tunnel, and verified by using the measured method, the measured results are highly consistent with the theoretical research results [6]. Heerden \& Sullivan of South Africa used CFD simulation method to study the air flow around the roadheader and the dust distribution around the roadheader in the coal mine [7]. K.W. Moloney, I.S. lowndes et al. [8] of the University of Nottingham, UK, have carried out a systematic study on the distribution of air flow when auxiliary ventilation is used in the underground single head tunnel, and compared with the conclusion of Johan van Heerden, a South African scholar, who uses the numerical simulation method, and finally reached the same conclusion.

In China, Wang Haiqiao et al. based on the hydrodynamics and jet theory, deeply analyzed the confined attached jet ventilation, elaborated the generation process and air flow structure of the driving ventilation jet, and provided the calculation formula of the average wind speed, maximum return speed and jet action distance of the air flow in the return area of the working face space flow field [9] [10] [11] [12]. Gao Jianliang, Henan University of technology, used FORTRAN language to simulate the flow field of forced local ventilation work- 
ing face, and obtained the numerical solution of 3D turbulence model [13].

To sum up, previous studies on the effective range of the pressure type local ventilation in the single head tunnel have found that when the wall jet in the single head tunnel develops to a certain extent, part of the air in the jet begins to return. This section is called the rotary section. The jet flow of the rotary section is the largest. After the rotary section, the flow gradually decreases. When the jet reaches the maximum range, the air flow is full the wind speed is zero [14]-[20]. Therefore, the horizontal distance from the jet exit section to the rotary section is defined as the range, but there is a low wind speed area at the end of the range which cannot completely and effectively release toxic and harmful gases. In this area, due to the small jet energy, it is unable to effectively eliminate the toxic and harmful gases produced in the process of driving, which seriously affects the safety of production of the mine. Therefore, it is reasonable to define the single head tunnel press in The effective range of local ventilation can not only improve the theory of local ventilation, but also prevent gas accumulation and ensure the safety of employees.

\section{Methods}

\subsection{Definition of Effective Range of Local Ventilation in Driving Face}

The minimum jet energy in the effective range area must be able to effectively eliminate the toxic and harmful gases produced in the process of driving, so as to ensure the basic requirements of safety and health of the operators. Therefore, on the basis of the previous definition of range, the requirements of the coal mine safety regulations on the lower limit of wind speed are added, that is, the minimum wind speed of the coal roadway in the driving face is $0.25 \mathrm{~m} / \mathrm{s}$, and the minimum wind speed of the rock roadway is $0.15 \mathrm{~m} / \mathrm{s}$. The low wind speed area that does not meet the requirements is removed, and the remaining range area length is defined as the effective range. In short, the effective range is the horizontal distance between the intersection point of the isoline of the lowest wind speed and the center line of the tunnel and the jet outlet.

\subsection{Scientific Verification of Reasonable and Effective Range Definition}

In order to prove the scientificity of the definition of effective range, the effective range and gas distribution of single air duct forced local ventilation in single head roadway are simulated by using fluid dynamics fluent simulation software.

1) Simulation analysis model of forced local ventilation in single head roadway

A physical model of single air duct forced ventilation in a single head roadway is established. The air duct is hung at the middle waist of the side wall of the roadway. The cross section size of the roadway is $3.3 \mathrm{~m} \times 5 \mathrm{~m}$, the length is 200 $\mathrm{m}$, the diameter of the air duct is $1 \mathrm{~m}$, and the length is $150 \mathrm{~m}$. 


\section{2) Mathematical model}

Considering that the air flow in driving tunnel is generally turbulent, the mass conservation equation, momentum conservation equation, standard $k-\varepsilon$ turbulence model equation and component transport equation are established, which are suitable for turbulence.

3) Setting of boundary conditions

The exit of the air duct is defined as vehicle inlet; the exit of the roadway is defined as outflow; the boundary condition around the roadway is set as wall. The fluid area is the space occupied by the tunnel to remove the air duct, and UDF files are compiled for the gas distribution during the coal tunnel driving. Assuming that the gas emission from the driving face, the roof and the side wall of the roadway is uniform at a distance of $50 \mathrm{~m}$ from the excavation head, the calculation formula of the gas emission source term is as follows:

$$
S_{i}=\frac{C Q \rho \varphi}{60 \mathrm{~V}}
$$

Formula 1 Calculation formula of gas emission source term

$S_{i}$ : gas gushing source term, $\mathrm{kg} \cdot \mathrm{m}^{-3} \cdot \mathrm{s}^{-1}$;

$C$ : gas concentration, \%;

$Q$ : air volume of tunnel, $\mathrm{m}^{3} / \mathrm{min}$;

$\rho$ : gas density, $0.719 \mathrm{~kg} / \mathrm{m}^{3}$;

$\mathrm{V}$ : volume of gas gushing source, $\mathrm{m}^{3}$;

$\varphi$ : proportional coefficient of gas gushing source term.

According to the actual measurement of a mine, it can be concluded that $q=$ $1200 \mathrm{~m}^{3} / \mathrm{min}, C=0.83 \%, \rho=0.719 \mathrm{~kg} / \mathrm{m}^{3}, \varphi=1, V=58.536 \mathrm{~m}^{3}$, in which $\mathrm{V}$ is calculated by the sum of the volume with the thickness of $0.1 \mathrm{M}$ of the head coal wall, the roof of the tunnel and the side wall of the tunnel. Substituting formula, $S_{i}=0.002038 \mathrm{~kg} \cdot \mathrm{M}^{-3} \cdot \mathrm{S}^{-1}$ is obtained.

4) Mesh division

According to the characteristics of the model, tetrahedron is used to divide the mesh, and the number of mesh is about 120,000 .

5) Numerical simulation

The unsteady state is used for simulation, and the time step is set as $20 \mathrm{~s}$. Since the model is a three-dimensional model, in order to study the gas migration in the tunnel, a horizontal section is made from the center of the air duct. The contour distribution of the wind speed above $0.25 \mathrm{~m} / \mathrm{s}$ is shown in Figure 1, and the corresponding gas concentration contour distribution is shown in Figure 2.

6) Result analysis

From Figure 1, it can be concluded that when the wind speed reaches 0.25 $\mathrm{m} / \mathrm{s}$ within the range, the horizontal distance from point a to the outlet of the air duct is $26.5 \mathrm{~m}$, which is the effective range. It can be seen from Figure 2 that the gas concentration isoline in front of the effective range position is very dense, and the average gas concentration rises sharply; while in the rear, the gas concentration isoline is sparse, and the average gas concentration drops sharply. It 


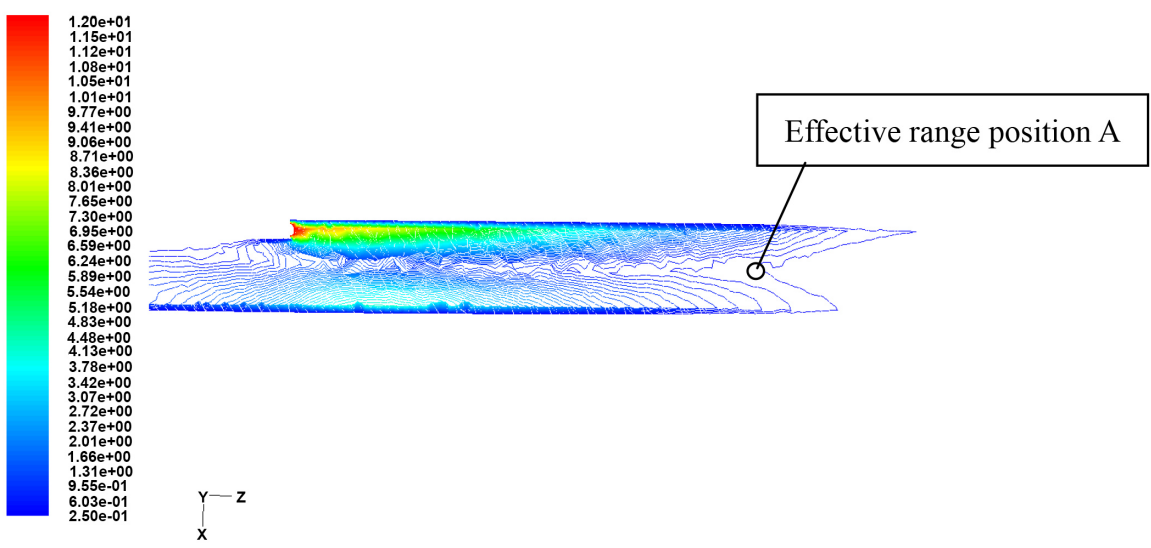

Figure 1. Distribution map of wind velocity field when air outlet velocity is $12 \mathrm{~m} / \mathrm{s}$ in single end tunnel.

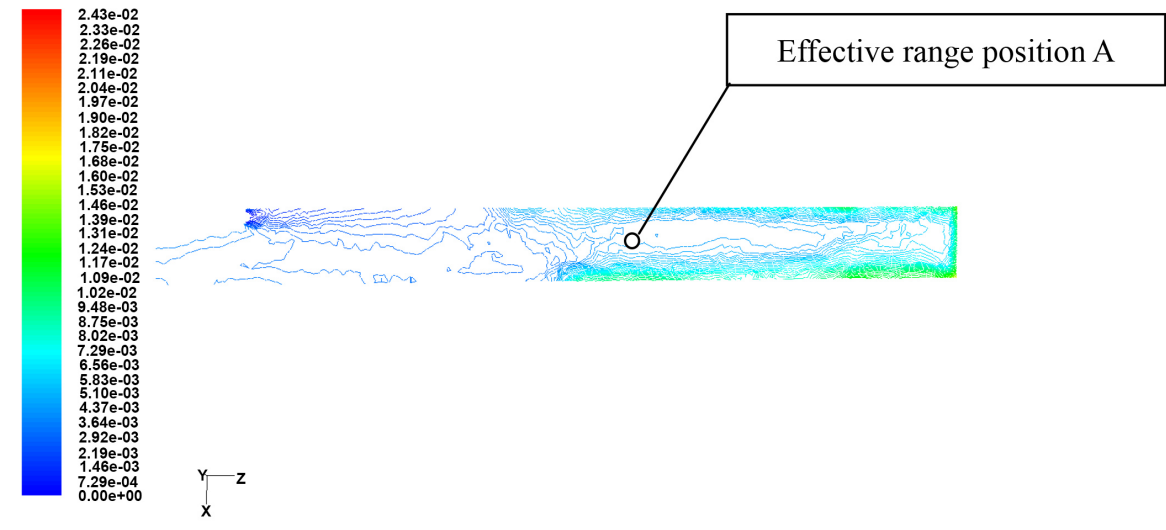

Figure 2. Distribution map of gas concentration when air outlet velocity is $12 \mathrm{~m} / \mathrm{s}$ in single end tunnel.

can be verified that the definition of effective range is in accordance with the actual law.

\subsection{Analysis of the Relationship between Wind Speed and Effective Range under Different Arrangement of Wind Tunnel}

According to the three different air duct arrangements of single air duct, double air ducts in common plane and two air ducts in parallel with each other with a distance of $5 \mathrm{~m}$, the relationship between the wind speed and the effective range of the driving face under different air duct arrangements is analyzed by using fluent fluid simulation software.

1) Establishment of physical model

The air duct of the forced ventilation is generally arranged on the side wall of the single head roadway, and the outlet of the air duct is generally located in the middle or on the side wall of the roadway, ensuring a certain distance from the head-on. In order to analyze the relationship between wind speed and effective range, a simplified model of wind speed and effective range is established (Table 1).

2) Mathematical model 
Table 1. The physical model of fan drum's different arrangement mode in forced ventilation.

\begin{tabular}{|c|c|c|c|}
\hline Arrangement of air duct & $\begin{array}{c}\text { Size of tunnel } \\
\text { (width } \times \text { height } \times \text { length })\end{array}$ & $\begin{array}{l}\text { Fan drum length } \\
\text { and diameter }\end{array}$ & Model section diagram \\
\hline Single fan drum wall-attached jet ventilation & $5 \mathrm{~m} \times 3.3 \mathrm{~m} \times 200 \mathrm{~m}$ & $\begin{array}{l}\text { length } 100 \mathrm{~m} \\
\text { diameter } 1 \mathrm{~m}\end{array}$ & \\
\hline $\begin{array}{l}\text { Parallel double fan drums wall-attached jet } \\
\text { ventilation (The difference between the two } \\
\text { air ducts is } 5 \mathrm{~m} \text { ) }\end{array}$ & $5 \mathrm{~m} \times 3.3 \mathrm{~m} \times 200 \mathrm{~m}$ & $\begin{array}{c}\text { length } 100 \mathrm{~m} \text { and } 95 \mathrm{~m} \text {, } \\
\text { diameter } 1 \mathrm{~m}\end{array}$ & \\
\hline $\begin{array}{l}\text { Double fan drums coplanar wall-attached } \\
\text { jet ventilation } \\
\text { (The two air ducts are the same length) }\end{array}$ & $5 \mathrm{~m} \times 3.3 \mathrm{~m} \times 200 \mathrm{~m}$ & $\begin{array}{c}\text { length } 100 \mathrm{~m} \text { and } 100 \mathrm{~m} \text {, } \\
\text { diameter } 1 \mathrm{~m}\end{array}$ & \\
\hline
\end{tabular}

In order to simplify the study, the following assumptions are made: the fluid in the tunnel can be regarded as incompressible fluid, ignoring the heat dissipation caused by the work of fluid viscosity, assuming the wall is adiabatic and isothermal ventilation; assuming the flow field has a high turbulence Reynolds number, the turbulence viscosity of the fluid is isotropic, and the turbulence viscosity coefficient can be treated as scalar; the flow is steady-state turbulence, meeting the Boussinesq false Set up. Therefore, the mathematical models of wind speed field simulation are mass conservation equation, momentum conservation equation and standard $\mathrm{k}-\varepsilon$ turbulence model equation.

3) Boundary conditions

The entrance boundary of the model is defined as the exit of the forced draft fan, the exit boundary is defined as the roadway section at the back of the fan, and the exit velocity of the fan is $v$. Therefore, the boundary conditions of the model can be described as follows:

Inlet boundary: $V_{x}=0, V_{y}=0, V_{z}=v$, turbulent kinetic energy $K=\frac{3}{2}(v I)^{2}$, turbulent kinetic energy dissipation rate $\varepsilon=C_{u}^{\frac{3}{4}} \frac{k^{\frac{3}{2}}}{l}$, in the formula, $I=0.16\left(\operatorname{Re}_{D H}\right)^{-\frac{1}{8}}, I=0.07 L, L$ is equivalent diameter, $C_{u}=0.084$.

Outlet boundary: $\frac{\partial V_{i}}{\partial X_{i}}=0, P=P_{\text {out }}$ relative pressure $P=0$.

Wall boundary: All of the wall is non-slip boundary, $V_{i}=0$; Wall is adiabatic; Pressure gradient which is vertical to wall surface is zero.

4) Grid division

According to the characteristics of the model, the Boolean operation is carried out, and the fluid region is obtained by subtracting the model of the air duct from the tunnel model. Under the Cartesian coordinate system, the calculation grid of the fluid region is divided, and the solution region is divided into tetra- 
hedral grid. The length of the tunnel (i.e. the length of the calculation area) is 1 , the width is $B$, the height is $h$, and the perimeter of the air duct is $c$. the grid density of the calculation area is $\mathrm{L} / 0.5$, the width direction is $\mathrm{B} / 0.1$, the height direction is $\mathrm{H} / 0.1$, and the perimeter position is $\mathrm{C} / 0.1$. The finite element grid is generated by mapping grid. The tetrahedron mesh is used to divide the single air duct model, and the mesh number is about 30,000; the tetrahedron and hexahedron hybrid mesh is used to divide the parallel $5 \mathrm{~m}$ model of the double air ducts, and the mesh number is about 50,000; the tetrahedron and hexahedron hybrid mesh is used to divide the coplanar model of the double air ducts, and the mesh number is about 50,000.

5) Analysis of simulation results

According to the above-mentioned local ventilation model of single head tunnel, when the wind speed at the outlet of the air duct is $4,6,8,10,12,14,16$, $18,20,30$ and $40 \mathrm{~m} / \mathrm{s}$ respectively, the relationship between the jet wind speed at the outlet of the air duct and the effective range under different air duct layout is studied. The simulation results are shown in Table 2.

According to the effective range obtained from Table 2 simulation, the simulation results of effective range of coal roadway and rock roadway under different outlet velocity of air duct are analyzed by data fitting. As an example, the fitting curve of the relationship between the parallel exit velocity and the effective range of the double air duct in the single head tunnel driving is shown in Figure 3. According to the different arrangement of the air duct, the curve equation of the relationship between the jet velocity at the outlet of the air duct and the effective range in the coal roadway and the rock roadway is respectively fitted, as shown in Table 3.

Table 2. Simulation results of effective range under different wind speed.

\begin{tabular}{|c|c|c|c|c|c|c|}
\hline \multirow{2}{*}{$\begin{array}{c}\text { Weed speed } \\
\mathrm{m} / \mathrm{s}\end{array}$} & \multicolumn{2}{|c|}{$\begin{array}{l}\text { Single fan drum } \\
\text { effective range } \\
(\mathrm{m})\end{array}$} & \multicolumn{2}{|c|}{$\begin{array}{c}\text { Parallel double fan drums } \\
\text { effective range } \\
\text { (m) }\end{array}$} & \multicolumn{2}{|c|}{$\begin{array}{c}\text { Double fan drums coplanar } \\
\text { effective range } \\
(\mathrm{m})\end{array}$} \\
\hline & $\begin{array}{c}\text { More than } \\
0.15 \mathrm{~m} / \mathrm{s}\end{array}$ & $\begin{array}{c}\text { More than } \\
0.25 \mathrm{~m} / \mathrm{s}\end{array}$ & $\begin{array}{c}\text { More than } \\
0.15 \mathrm{~m} / \mathrm{s}\end{array}$ & $\begin{array}{c}\text { More than } \\
0.25 \mathrm{~m} / \mathrm{s}\end{array}$ & $\begin{array}{c}\text { More than } \\
0.15 \mathrm{~m} / \mathrm{s}\end{array}$ & $\begin{array}{c}\text { More than } \\
0.25 \mathrm{~m} / \mathrm{s}\end{array}$ \\
\hline 4 & 18.1 & 12.4 & 19.3 & 19.16 & 17.7 & 13.54 \\
\hline 6 & 23.5 & 14.4 & 22.96 & 19.21 & 27.24 & 17.11 \\
\hline 8 & 25.9 & 19.3 & 29.2 & 20.31 & 33.2 & 20.79 \\
\hline 10 & 27.9 & 20.7 & 35.15 & 24.57 & 34.24 & 27.26 \\
\hline 12 & 30 & 26.5 & 39.25 & 29.09 & 42.9 & 33 \\
\hline 14 & 32 & 28.6 & 42.14 & 35.01 & 43.76 & 34.01 \\
\hline 16 & 31.9 & 28 & 43.7 & 38.34 & 44.37 & 34.19 \\
\hline 18 & 35.1 & 29.7 & 45.24 & 39.4 & 45.14 & 37.67 \\
\hline 20 & 35.4 & 28.3 & 47.67 & 41 & 47.46 & 43.05 \\
\hline 30 & 36.1 & 33.4 & 49.87 & 43.65 & 55.2 & 47.15 \\
\hline 40 & 36.4 & 35.4 & 49.6 & 43.04 & 59.34 & 48.64 \\
\hline
\end{tabular}


Table 3. The fitting curves of effective range's simulation results under different wind speed.

\begin{tabular}{cccc}
\hline $\begin{array}{c}\text { Fan drum } \\
\begin{array}{c}\text { arrangement } \\
\text { mode }\end{array}\end{array}$ & $\begin{array}{c}\text { The lowest } \\
\text { weed speed } \\
\text { isoline }\end{array}$ & Fitting curves & $\begin{array}{c}\text { Correlation } \\
\text { coefficient }\end{array}$ \\
\hline Single fan drum & $0.15 \mathrm{~m} / \mathrm{s}$ & $y=0.0009 x^{3}-0.0811 x^{2}+2.5332 x+10.004$ & 0.9869 \\
& $0.25 \mathrm{~m} / \mathrm{s}$ & $y=0.0011 x^{3}-0.0983 x^{2}+2.9786 x+1.1508$ & 0.9693 \\
$\begin{array}{c}\text { Parallel double } \\
\text { fan drums }\end{array}$ & $0.15 \mathrm{~m} / \mathrm{s}$ & $y=0.0014 x^{3}-0.135 x^{2}+4.3948 x+2.7193$ & 0.9943 \\
$\begin{array}{c}\text { Double fan } \\
\text { drums coplanar }\end{array}$ & $0.25 \mathrm{~m} / \mathrm{s}$ & $y=-0.0002 x^{3}-0.0241 x^{2}+2.2148 x+7.5535$ & 0.953 \\
\hline
\end{tabular}

The relationship between wind speed and effective range in coal tunnel

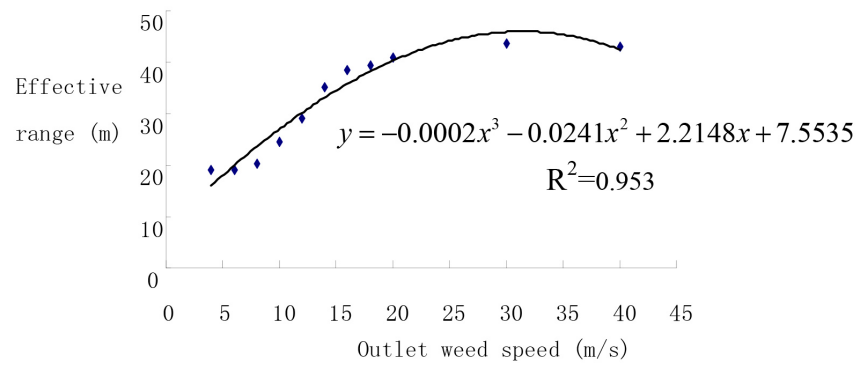

(a) when the lowest weed speed is $0.25 \mathrm{~m} / \mathrm{s}$

The relationship between wind speed and effective range in rock tunnel

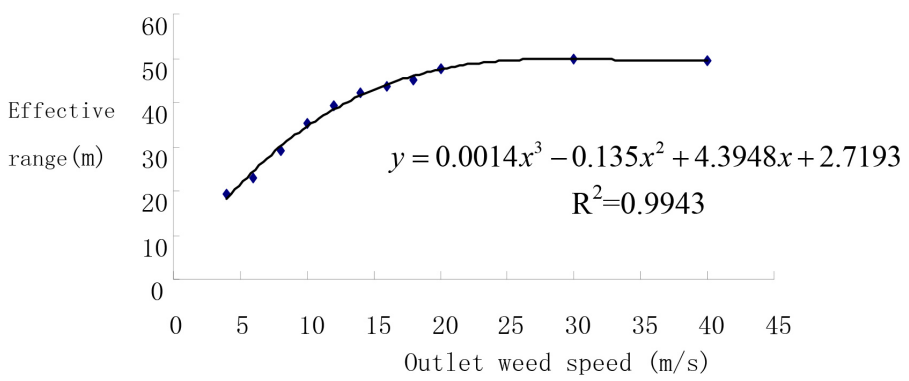

(b) when the lowest weed speed is $0.15 \mathrm{~m} / \mathrm{s}$

Figure 3. Fitting curve of the relationship between wind speed and effective range in single end tunnel with double fan drums coplanar.

The above fitting curves are obtained by cubic polynomial fitting, and the correlation coefficient $\mathrm{R}^{2}$ is greater than 0.95 , so the fitting has a high correlation. From the above fitting curve, it can be seen that when the wind speed at the outlet of the air duct reaches $20 \mathrm{~m} / \mathrm{s}$, the effective range gradually keeps stable, that is, the influence of the wind speed on the effective range gradually weakens.

\section{Results and Discussion}

The effective range of forced ventilation is redefined by the contour of the minimum allowable wind speed in the horizontal section of the tunnel center, and the numerical simulation method of the relationship between the effective range 
of forced local ventilation and the jet wind speed at the outlet of the single air duct, the double air duct and the coplanar and parallel air duct are put forward, and the corresponding relationship model is established.

The rationality and scientificity of the definition of effective range are verified by numerical simulation. It is found that the gas concentration isoline in front of the effective range position is very dense, and the average gas concentration rises sharply; while in the back, the gas concentration isoline is sparse, and the average gas concentration drops sharply. It shows that the redefined effective range can effectively eliminate toxic and harmful gases, and can meet the requirements of safety production.

When the wind speed at the outlet of the air duct is less than $20 \mathrm{~m} / \mathrm{s}$, the effective range changes faster with the outlet wind speed. When the wind speed exceeds $20 \mathrm{~m} / \mathrm{s}$, the effective range changes less with the speed, that is, the effect of wind speed on the effective range decreases gradually. Under the same exit wind speed, the effective range of parallel and coplanar air inlet is much greater than that of single air inlet.

\section{Conflicts of Interest}

The authors declare no conflicts of interest regarding the publication of this paper.

\section{References}

[1] Wen, D.S., Li, Z.N. and Huang, Z.H. (2004) Engineering Fluid Mechanics. Higher Education Press, Beijing, 214-235.

[2] Wang, Y.M. (1994) Mine Aerodynamics and Ventilation System. Metallurgical Industry Press, Beijing, 71-77.

[3] Ichinose, M. (1998) In-Situ Measurement and Simulation by CFD of Methane Gas Distribution at a Heading Face Shigen-to-Sozaiv.

[4] Rao, S., Baafi, E.Y., Aziz, N.I. and Singh, R.N. (1993) Three Dimensional Numerical Modeling of Air Velocity and Dust Control Techniques in a Longwall Face. 6th US Mine Ventilation Symposium, Salt Lake City, UT, 21-23 June 1993.

[5] Tomita, S., Inoue, M. and Uchino, K. (1999) Behavior of Airflow and Methane at Heading Faces with Auxiliary Ventilation System. Proceedings of the 1999 International Symposium on Mining Science and Technology, Beijing, 29-31 August 1999, 69-72.

[6] Konduri, I.M. (1997) Experimental and Numerical Modeling of Jet Fans for Auxiliary Ventilation in Mines. Proceedings of the 6 th International Mine Ventilation Congress, Pittsburgh, PA, 17-22 May 1997, 505-512.

[7] Heerden, J. and Sullivan, P. (1993) The Application of CFD for Evaluation of Dust Suppression and Auxiliary Ventilation Systems Used with Continuous Miners. 6 th US Mine Ventilation Symposium, Salt Lake City, UT, 21-23 June 1993.

[8] Moloney, K.W., Lowndes, I.S., Stoches, M.R. and Hargrave, G. (1997) Studies on Alternative Methods of Ventilation Using Computational Fluid Dynamics, Scale and Full Scale Gallery Tests. Proceedings of the 6 th International Mine Ventilation Congress, Pittsburgh, PA, 17-22 May 1997. 
[9] Wang, H.Q., Shi, S.L., Liu, R.H. and Liu, H.Q. (2003) CFD Simulation Study on Jet Flow Field of Single Head Tunnel. Chinese Journal of Safety Sciences, No. 1, 68-71.

[10] Wang, H.Q., Liu, R.H. and Chen, S.Q. (2004) Experimental Study on the Flow Field Characteristics of Confined Attached Jet in Single Head Tunnel. China Engineering Science, No. 8, 45-49.

[11] Wang, H.Q. (1999) Study on Jet Flow Field in Driving Face. Journal of Coal, No. 5, 500-502.

[12] Gao, J.L., Xu, K.L. and Wu, Y. (2009) Numerical Experimental Study on Gas Distribution in Driving Tunnel. Chinese Journal of Safety Sciences, No. 1, 18-24.

[13] Li, E.L., Wang, B.Q. and Wang, Z.C. (1986) Experimental Study on Turbulent Diffusion and Dispersion in Tunnels. Journal of Northeast Institute of Technology, No. 2, 38-43.

[14] He, L. and Zhang, S.J. (2012) Study on the Law of Smoke Diffusion in the Vein Driving Roadway of Xitieshan Mine Based on CFD. China Mining Engineering, No. $5,4-6$.

[15] Cao, Y., Ji, H.G. and Zhou, Q.M. (2017) Calculation of Smoke Exhaust Time after Tunnel Blasting. Journal of Harbin University of Technology, No. 8, 136-139.

[16] Liu, Z.C., Chai, J.R. and Jia, X.M. (2009) Numerical Simulation of Harmful Gas Concentration Diffusion in Driving Face with Forced Ventilation. Geotechnical Mechanics, No. 2, 30-34.

[17] Ye, Y.J., Jiang, J.T. and Ding, D.X. (2015) The Migration Rule of Radon and Smoke after Blasting in Single Head Tunnel. Chinese Journal of Safety Sciences, No. 5, 131-137.

[18] Yang, L.X., Lu, M.C. and Zhao, J.X. (2000) Discussion on Calculation of Ventilation and Smoke Exhaust Air Volume after Blasting in Tunnel Construction. Western Exploration Engineering, No. 1, 55-56.

[19] Su, L.J. and Lu, W.B. (2000) Smoke Diffusion and Ventilation in Underground Tunnel Drilling and Blasting. Blasting, No. 1, 1-6.

[20] Nan, C.Z., Zhang, W.H. and Zhao, X. (2014) Numerical Simulation of Ventilation Harmful Gas Diffusion during Construction of Complex Cavern Group. Journal of Tsinghua University (Natural Science Edition), No. 8, 93-98. 